\title{
PENDUGAAN MODEL PERAMALAN HARGA EKSPOR KOPI INDONESIA
}

\section{ESTIMATION FORECASTING MODEL FOR THE EXPORT PRICE OF INDONESIAN COFFEE}

\author{
Emlan Fauzi, Wawan Eka Putra, Andi Ishak dan Herlena Bidi Astuti \\ Balai Pengkajian Teknologi Pertanian Bengkulu \\ Email : emlan.81@gmail.com
}

\begin{abstract}
ABSTRAK
Penelitian ini bertujuan untuk menguji model peramalan terbaik untuk harga ekspor kopi Indonesia. Data yang digunakan dalam kajian ini adalah data bulanan harga kopi dari bulan Januari 2012 sampai dengan September 2019. Tiga model peramalan harga yang digunakan yaitu moving avergae, pemulusan eksponensial tunggal dan trend analisis diterapkan untuk menentukan model terbaik berdasarkan nilai MAPE, MAD, dan MSE terendah. Hasil penelitian menunjukkan model yang terbaik untuk meramalakan harga ekspor kopi adalah model moving average (MA1) karena memiliki nilai MAPE, MAD dan MSE terkecil dibandingkan dengan model lainnya.
\end{abstract}

Kata kunci: Harga; Kopi; Peramalan; Ekspor

\section{ABSTRACT}

This study aims to examine the best forecasting model for the export price of Indonesian coffee. The data used in this study are monthly data on coffee prices from January 2012 to September 2019. Three price forecasting models used are moving average, single exponential smoothing and trend analysis are applied to determine the best model based on the lowest MAPE, MAD, and MSE values. The results showed the best model for forecasting the export price of coffee is the moving average (MA1) model because it has the smallest MAPE, MAD and MSE values compared to other models.

Keywords: Price; Coffee; Forecasting; Export

\section{PENDAHULUAN}

Kopi merupakan produk perkebunan yang mempunyai peluang pasar, baik di dalam negeri maupun di luar negeri. Sejak tahun 1984 pangsa ekspor kopi Indonesia di pasar kopi internasional menduduki nomor tiga tertinggi setelah Brazilia dan Kolombia, bahkan untuk kopi jenis robusta ekspor Indonesia menduduki peringkat pertama di dunia. Sebagian besar ekspor kopi Indonesia adalah jenis kopi robusta (94\%), dan sisanya adalah kopi jenis arabika (Chandra et al, 2013).

Pada era liberalisasi perdagangan saat ini, sebenarnya menjadi peluang bagi perdagangan kopi robusta Indonesia di pasar internasional.Hambatan ekspor dalam bentuk tarif berangsur-angsur akan 
hilang dan hal ini akan mengurangi beban eksportir kopi nasional, yang selanjutnya juga akan menguntungkan petani kopi Indonesia (Yahmadi, 2005).

Kondisi ekspor kopi Indonesia mempunyai daya saing yang kuat, selain itu komoditas bijikopi Indonesia mampu merebut pangsa pasar komoditas biji kopi di pasar global serta trend ekspor biji kopi Indonesia mempunyaitrend yang menguat dari tahun 2002 hingga tahun 2017, serta Indonesia mempunyai biaya produksi biji kopi yang rendah dibandingkan Brazil danVietnam dan mempunyai kondisifaktor yang mendukung daya saing ekspor kopi Indonesia di pasar global (Alexander dan Nadapdap, 2019).

Pada tahun 2009 volume ekspor kopi robusta Indonesia meningkat menjadi 434.430 ton dari tahun sebelumnya 2008 sebanyak 348.187 ton. Kemudian pada tahun 2011 volume ekspor kopi robusta Indonesia menurun menjadi 265.368 ton. Nilai ekspor kopi Indonesia berfluktuatif. Fluktuasi nilai ekspor lebih dipengaruhi oleh perubahan harga kopi dibandingkan dengan perubahan volume ekspor (AEKI, 2012).Sehingga apabila situasipasar internasionaltidak menentu dampaknya akansangat dirasakan oleh petani kopi rakyat. Oleh karena itu, perlu dilakukan upaya penting untuk menjaga stabilitas ekspor kopi adalah dengan memonitoring harga ekspor dan peramalan ekspor. Dengan mengetahui harga ekspor dimasa lalu maka akan dapat menduga harga ekspor dimasa yang akan datang. Berdasarkan uraian di atas, maka tujuan dari kajian ini adalah menentukan modelyang terbaik untuk peramalan harga ekspor kopi indonesia.

\section{METODE PENELITIAN}

Kajian ini menggunakan data bulanan harga ekspor kopi indonesia dalam dolar per kilogram (US\$/kg) yang terdiri dari 93 periode(bulan). Sumber data yang digunakan dalam penelitian ini adalah data sekunder, yaitu data yang diperoleh dari pihak lain, dan diolah kembali untuk kepentingan kajian ini yaitu data harga ekspor kopibulanan selama bulan Januari 2012 hingga September 2019. Dalam menganalisis harga ekspor kopi indonesia ini digunakan metode forecasting (peramalan) yaitu:

\section{Rata-rata Bergerak (Moving Average)}

Peramalan rata-rata bergerak menggunakan sejumlah data aktual masa lalu untuk menghasilkan peramalan. Ratarata bergerak berguna jika kita dapat mengasumsikan bahwa permintaan pasar akan stabil sepanjang masa yang diramalkan(Gaspersz, 2008). Secara matematis, rata-rata bergerak sederhana (merupakan prediksi permintaan periode mendatang) dinyatakan sebagai berikut: 


$$
S_{t+1}=\frac{X_{t}+X_{t-1}+\ldots+X_{t-n+1}}{n}
$$

$\mathrm{S}_{\mathrm{t}+1}=$ permalan periode $\mathrm{ke} \mathrm{t}+1$

$\mathrm{X}_{\mathrm{t}}=$ data periode $\mathrm{ke} \mathrm{t}$

$\mathrm{n} \quad=$ jangka waktu

Moving averages dan nilai $\mathrm{n}$ merupakan banyaknya periode dalam $1+t$ rata-rata bergerak (Garpersz, 2008).

\section{Penghalusan Eksponensial (Single}

\section{Exponential Smoothing)}

Penghalusan

eksponensial

merupakan metode peramalan rata-rata bergerak denganpembobotan yang canggih tetapi masih mudah digunakan. Metode ini menggunakan pencatatan datamasa lalu yang sangat sedikit. Rumus penghalusan eksponensial dasar dapat ditunjukkan sebagaiberikut:

$$
F_{t}=F_{t-1}+\alpha\left(A_{t-1}-F_{t-1}\right)
$$

dengan:

$\mathrm{F}_{\mathrm{t}} \quad=$ peramalan baru

Ft-1 = peramalan sebelumnya

A $=$ konstanta penghalusan

(pembobotan) $(0=\mathrm{a}=1)$

At-1 = permintaan aktual periode lalu

Konstanta penghalusan untuk

penerapan di bidang bisnis biasanya berkisar dari 0,05 hingga 0,5. Pendekatan penghalusan eksponensial mudah digunakan dan telah berhasil diterapkan pada hampir setiap jenis bisnis. Walaupun demikian, nilai yang tepat untuk konstanta penghalusan dapat membuat diferensiasi antara peramalan yang akurat dan yang tidak akurat. Nilai a yang tinggi dipilih pada saat rata-rata cenderung berubah.
Nilai a yang rendah digunakan saat ratarata cukup stabil. Tujuan pemilihan suatu nilai untuk konstanta penghalusan adalah mendapatkan peramalan yang akurat.

\section{Analisis Tren (Trend Analysis)}

Teknik ini mencocokkan garis tren pada serangkaian data masa lalu, kemudianmemproyeksikan garis pada masa datang untuk peramalan jangka menengah atau jangka panjang.

$\hat{y}=a+b X$ dengan:

$\hat{y}=$ nilai terhitung dari variabel yang akan diprediksi (variabel terkait)

$\mathrm{a}=$ persilangan sumbu $\mathrm{y}$

$\mathrm{b}=$ kemiringan garis regresi (tingkat perubahan pada y untuk perubahan yang terjadi di $\mathrm{x}$ )

$\mathrm{x}=$ variabel bebas

$$
\begin{gathered}
\mathbf{b}=\frac{\sum \mathrm{xy}-\mathrm{n}(\bar{x})(\bar{y})}{\sum \mathrm{x}^{2}-\mathrm{n}(\bar{x})^{2}} \\
\bar{y}=\mathbf{a}+\mathbf{b}(\mathbf{x})
\end{gathered}
$$

$$
\begin{array}{ll}
\mathrm{x} & =\text { nilai variabel bebas yang diketahui } \\
\mathrm{y} & =\text { nilai variabel terkait yang diketahui } \\
\mathrm{X} & =\text { rata-rata nilai } \mathrm{x} \\
\mathrm{Y} & =\text { rata-rata nilai } \mathrm{y} \\
\mathrm{n} & =\text { jumlah data atau pengamatan }
\end{array}
$$

\section{Pengukuran Akurasi Hasil Peramalan}

Menurut Hanke dan Wichern (2005), ukuran akurasi hasil peramalan ada 2 ukuran yang biasa digunakan, yaitu rata-rata deviasi mutlak (Mean Absolute Devitation = MAD) dan rata- rata kuadrat kesalahan (Mean square error $=\mathrm{MSE})$. Lebih lanjut Nasution \& Prasetyawan, (2008); Krajewski and Ritzman, (1993) 
menyatakan bahwa Indikator yang digunakan dalam penentuan model peramalan terbaik adalah rata-rata kesalahan absolut (MAD), rata-rata kesalahan kuadrat (MSE), dan rata-rata persentase kesalahan absolut (MAPE).

\section{HASIL DAN PEMBAHASAN}

\section{Gambaran Harga Ekspor Kopi Indonesia}

Volume ekspor kopi Indonesia per April 2019 mencapai 94,5 ribu ton dengan nilai sebesar US\$259,5 juta. Sementara itu, tahun 2018, volume ekspor sebesar 280 ribu ton menurun sebesar 40 persen dibandingkan tahun sebelumnya. Nilai ekspor 2018 juga menurun dari US\$1,2 miliar menjadi US\$817,8 juta (BPS, 2019).Nilai ekspor kopi yang relatif fluktuatif sangat dipengaruhi oleh harga kopi dunia. Harga tersebut terdapat komponen trend dan variasi musiman. Komponen trend dikenali dengan adanya kenaikan atau penurunan series yangmonoton atau pun adanya ketidakstabilan pada nilai rata-rata, sementarafaktor musiman berkaitan dengan fluktuasi periodik yang berulang dalamwaktu satu tahun yang disebabkan oleh temperatur, curah hujan, bulan padasuatu tahun, dan lain-lain. Tabel 1 menunjukkan ringkasan statistik dari dataharga ekspor kopi indonesia.

Dari Tabel 1 diketahui bahwa nilai rata-rata harga ekspor kopi dari periodeJanuari 2012 hingga september 2019 terus mengalami fluktuasi harga. Sementara,untuk penyimpangan data tersebut terhadap rata-ratanya relatif bervariasiyakni berkisar antara nilai 0,122 hingga 0,752 .

Tabel 1. Hasil Ringkasan Statistik Dari Dataharga Ekspor Kopi Indonesia Bulanan

\begin{tabular}{lcccccccc}
\hline & $\mathbf{2 0 1 2}$ & $\mathbf{2 0 1 3}$ & $\mathbf{2 0 1 4}$ & $\mathbf{2 0 1 5}$ & $\mathbf{2 0 1 6}$ & $\mathbf{2 0 1 7}$ & $\mathbf{2 0 1 8}$ & $\mathbf{2 0 1 9}$ \\
\hline Mean & 3,047 & 2,246 & 2,721 & 2,439 & 2,467 & 2,562 & 3,103 & 2,669 \\
Standar Deviasi & 0,608 & 0,247 & 0,305 & 0,273 & 0,177 & 0,122 & 0,752 & 0,356 \\
\hline
\end{tabular}

Sumber: Data diolah, 2019

\section{Hasil Estimasi Model Peramalan}

Untuk melihat harga ekspor kopi indonesia pada beberapa waktu ke depan dapat digunakan beberapa metode peramalan, antara lain Metode Moving Average(MA), Metode Exponential Smoothing dan Analisis Trend. Berikut analisis dan peramalan data ekspor lada indoensia:

\section{Metode Moving Average (MA)}

Berdasarkan dari ketiga gambar tersebut, terlihat bahwa garis yang mewakili nilai peramalan yang hampir 
berhimpit atau paling mendekati garis yang mewakili nilai aktual adalah nilai peramalan yang dihasilkan oleh MA(1). Sementara untuk nilai peramalan yang dihasilkan oleh MA(2) dan MA(3) tidak terlalu berhimpit dengan garis yang mewakili nilai aktualnya seperti terlihat pada gambar 1 .

MA(1) merupakan model yang menghasilkan nilai ramalan palingbaik. Interpretasi secara visual tersebut sejalan dengan hasil yang diperolehberdasarkan nilai MSE, MAPE dan MAD seperti yang disajikan Tabel 2.

Berdasarkan Tabel 2, didapat bahwa MA(1) memiliki nilai MSE terkecil dibandingkan dengan MA(2) dan MA(3). Begitu juga dengan nilai MAPE dan
MAD. Dengan demikian, untuk kasus peramalan jumlah harga ekspor kopi indonesia model Moving Average yang sesuai yakni MA(1) dengan nilai ramalan harga ekspor untuk periode ke-94 (Bulan Oktober 2019), yakni sebesar $1,961 \mathrm{US} \$ / \mathrm{kg}$. Hasil peramalan tersebut menginformasikan bahwa harga ekspor kopi indonesia pada Bulan Oktober 2019yaitusebesar1,961 US\$ per kilogram atau sama dengan bulan sebelumnya. Hasil penelitian ini sejalan dengan penelitian Sukiyono dan Rosdiana (2018), yang menyatakan model MA adalah modelterbaik untuk meramalkan harga beras pada tingkat pedagang besar di Provinsi Bengkulu.

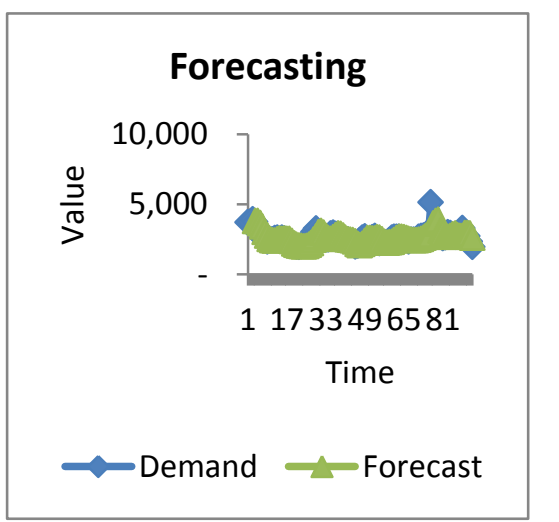

MA (1)

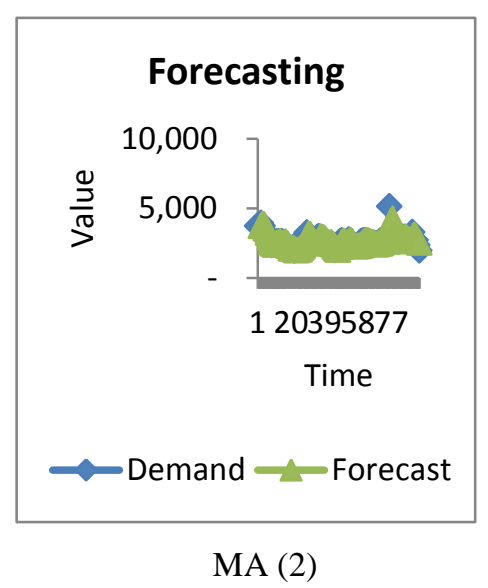

MA (2)

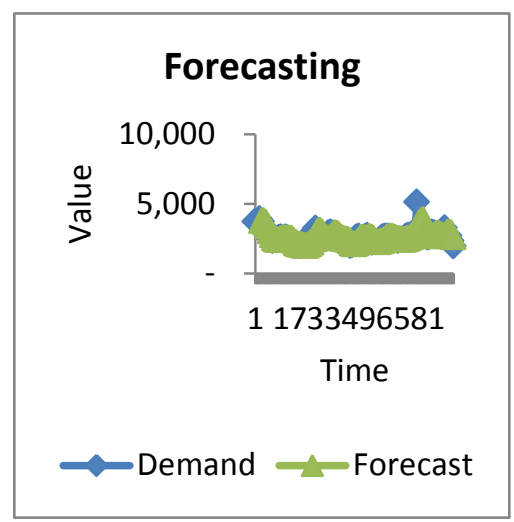

MA (3)

Gambar 1. Hasil Estimasi Model Peramalan dengan Model Moving Average

Tabel 2. Perbandingan Hasil Ramalan dengan Model MA

\begin{tabular}{lrrr}
\hline & MA(1) & MA(2) & MA(3) \\
\hline Nilai Error pada Metode MA & & & 0,33 \\
\hline MAD & 0,19 & 0,27 & 0,46 \\
MSE & 0,12 & 0,28 & 11,34 \\
MAPE & 6,71 & 9,25 & 2,343 \\
\hline Nilai Peramalan (US\$/kg) & 1,961 & 2,158 &
\end{tabular}

Sumber: Data diolah, 2019 
Penghalusan Eksponensial (Single Exponential Smoothing)

Menurut Render dan Heizer (2005),penghalusan exponential adalah teknik peramalan rata-rata bergerak denganpembobotan dimana data diberi bobot oleh sebuah fungsi exponential. Metode ini hanya mampu memberikan ramalan satu periode ke depan dan cocok untuk data yang mengandung stationer. Metode ini membutuhkan nilai alfa $(\alpha)$ sebagai nilai parameter pemulusan. Nilai $\alpha$ dilakukan dengan membandingkan menggunakan interval pemulusan antara $0<\alpha<1$, yaitu $\alpha(0,1$ sampai dengan 0,9$)$. Hasil estimasi model dengan menggunakan berbagai tingkat $\alpha$ disajikan pada Tabel 3.
Berdasarkan tabel 3 terlihat bahwa perhitungan dengan membandingkan nilai $\alpha$ maka didapat koefisien $\alpha$ sebesar 0,9 yang memiliki nilai MAD terkecil yaitu sebesar 0,19, nilai MSE sebesar 0,12 dan MAPE sebesar 6,85. Persamaan yang terbentuk adalah $S_{t}=0,9 y_{t}+(1-0,9) S_{t-1}$. Dari persamaan tersebut maka dapat ditentukan nilai peramalan satu periode berikutnya yaitu bulan Oktober 2019 sebesar 2,004US\$/kgharga ekspor kopi indonesia.Hasil penelitian ini sejalan dengan penelitian Sukiyono, (2018) yang menyatakan bahwa Metode Single Exponential dengan $\alpha=0.9$, dimana perolehan nilai MSE sebesar 26005.1, MAD sebesar 120.2, dan MAPE sebesar 120.2 .

Tabel 3. Hasil Perbandingan Nilai Kesalahan Metode Single Eksponential Smoothing dengan Nilai $\alpha$ Berbeda-Beda.

\begin{tabular}{cccr}
\hline Alfa $(\alpha)$ & MAD & MSE & MAPE \\
\hline 0,1 & 0,32 & 0,22 & 12,50 \\
0,2 & 0,25 & 0,15 & 9,39 \\
0,3 & 0,25 & 0,15 & 9,39 \\
0,4 & 0,24 & 0,13 & 8,81 \\
0,5 & 0,23 & 0,12 & 8,25 \\
0,6 & 0,22 & 0,12 & 7,79 \\
0,7 & 0,21 & 0,12 & 7,40 \\
0,8 & 0,20 & 0,12 & 7,09 \\
0,9 & 0,19 & 0,12 & 6,85 \\
\hline
\end{tabular}

Sumber: Data diolah, 2019

\section{Analisis Tren (Trend Analysis)}

Berdasarkan pola hubungan linier antara harga ekspor kopi sebagai variabel dependen dan periode waktu sebagai variabel independen, terlihat bahwa hubungan variabel tersebut berada diantara garis lurus, berarti residual berdistribusi normal dengan rata-rata mendekati nol. Dengan nilai MSE sebesar 0,217, nilai MAD sebesar 0,309 dan nilai 
MAPE sebesar 11,39. Pergerakan grafik peramalan menggunakan metode trend analysis dengan model regresi linier sederhana dengan harga ekspor kopi indonesia sebagai dependent variabel dan periode waktu sebagai indpendent variabel disajikan pada gambar 2 .

\section{Pemilihan Model Terbaik}

Pemilihan metode terbaik dilakukan dengan membandingkan nilai MSE, MAPE dan MAD dari masing- masing metode yang terpilih. Untuk lebih jelasnya dapat dilihat pada Tabel 6 .
Tabel 6 menunjukkan bahwa berdasar kriteria MSE, MAD dan MAPE, modelyang paling baik digunakan untuk meramalkanharga eksporkopi indonesia adalah metode MA 1. Harga ekspor kopi indonesia ramalan pada Bulan oktober 2019 diperoleh sebesar US\$. 1,961. Hasil penelitian ini sejalan dengan penelitian Sukiyono et al (2018); Novanda et al (2018); Putri et al (2019); Eka Ferri Indayani (2009) dan Mei Taripar Pardamean (2010) yang menyatakan bahwa model yang terbaik dari dari banyak model yang digunakan dalam peramalan adalah model MA dan ARIMA.

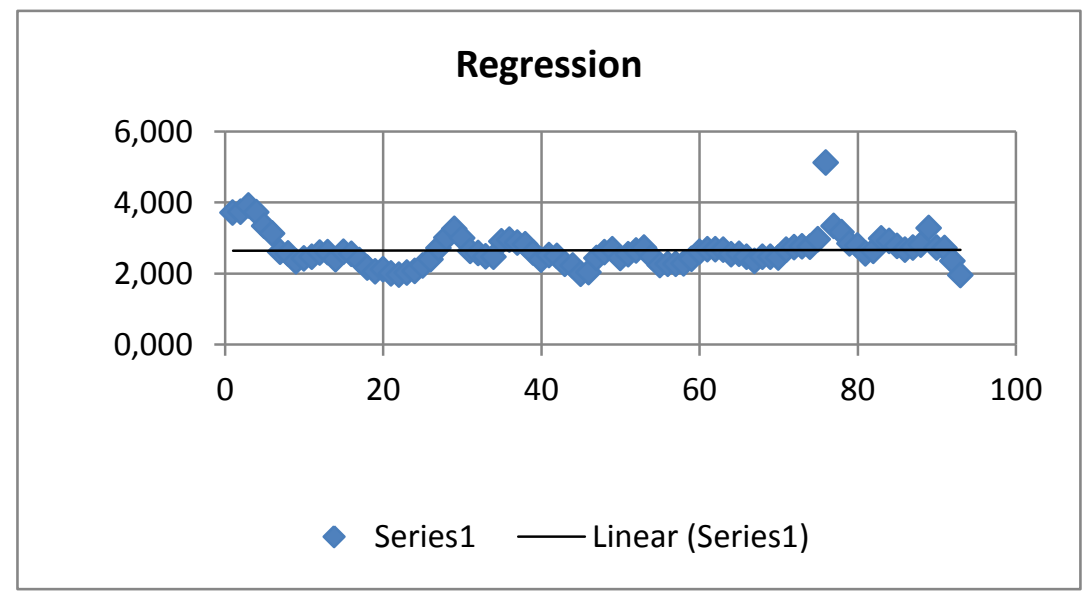

Gambar 2. Grafik Trend Analysis Model Regresi linear.

Tabel 6 Perbandingan Kriteria Kebaikan Antar Metode

\begin{tabular}{lcccc}
\hline \multirow{2}{*}{ Model Peramalan } & \multicolumn{3}{c}{ Ukuran Akurasi } & \multirow{2}{*}{ Kesimpulan } \\
\cline { 2 - 4 } & MAD & MSE & MAPE & \multirow{2}{*}{ MA (1) } \\
\hline Moving Average (1) & 0,19 & 0,12 & 6,71 & \\
Single Exponential & 0,19 & 0,12 & 6,85 & \\
Smoothing (a=0,9) & & & & \\
Trend Analysis & 0,32 & 0,22 & 11,39 & \\
\hline
\end{tabular}

Sumber: Data diolah, 2019 


\section{KESIMPULAN}

Hasil kajian di atas dapat disimpulkan bahwa model MA(1) adalah modelterbaik jika peramalan model harga ekspor kopi indonesia pada tingkat internasionaldilakukan menggunakan model Moving Average. Jika menggunakan modelSingle exponential, model dengan $\alpha=0,9$ adalah model yang terbaik. Pemilihan didasarkan pada kriteria MSE, MAPE dan MAD terkecil, maka model moving average (1) adalahmodel terbaik jika dibandingkan model lainnya.

\section{SARAN}

Peramalan dengan metode time series akan lebih akurat jika data yang digunakan lebih banyak karena nilai MSE sangat tergantung pada banyaknya data yang digunakan dalam peramalan. Berangkat dari hasil kajian di atas, perlu kehati-hatian dalam pemilihanmodel peramalan terbaik, khusunya jika jumlah data yang digunakan jugaberubah. Perlu dilakukan perbandinagn model lain yang mungkin akanmenghasilkan hasil yang berbeda, seperti double exponential smoothing,linear, atau model yang lain.

\section{DAFTAR PUSTAKA}

AEKI. (2012). Areal dan Produksi.AEKI. Alexander, Ivan dan Nadapdap, Hendrik Johannes. 2019. Analisis Daya Saing Ekspor Biji Kopi Indonesia di
Pasar Global Tahun 2002-2017. JSEP 12(2): 1-16

Chandra, Devi, R. Hanung Ismono, Eka

Kasymir. 2013. Prospek

Perdagangan Kopi Robusta

Indonesia di Pasar Internasional.

JIIA, 1(1): 10-15.

Gaspersz, V. 2008. Production Planning \& Inventory Control, Jakarta, Gramedia.

Hanke, John E \& Wichern, Dean W. (2005). Busines Forecasting. New Jersey: Pearson Education.

Heizer Jay, Render Barry. 2005. Operations Management. Jakarta: Salemba. Empat.

Indayani, E. , F. 2009. Peramalan JumlahPenumpang Kereta Api Dengan Menggunakan Metode BoxJenkins (Studi Kasus di PT. Kereta Api (Persero) DAOP VI Yogyakarta).E-journal. UIN Sunan Kalijaga Yogyakarta.

Kementan. 2018. Potensi Ekspor Komoditas Pertanian Indonesia. Jakarta.

Khair, Aulia. 2011. Peramalan Beban Listrik Jangka Pendek Menggunakan Kombinasi Dengan Autoregresive Integreted Moving Average (ARIMA) dengan Regresi Linier Antara Suhu dan Daya Listr ik. E-jurnal . Universitas Indonesia.

Krajewski, Lee J., and Larry P. Ritzman. 1993. Operations Management: Strategyand Analysis, 5th Edition. Pearson

Maryadi, Atang Sutandi, Ivanovich Agusta. 2016. Analisis Usaha Tani Lada dan Arahan Pengembangannya di Kabupaten Bangka Tengah. JSEP 9 (2).23-29.

Nasution, A. H., dan Prasetyawan. 2008. Perencanaan dan PengendalianProduksi. Yogyakarta : Graha Ilmu.

Novanda, Rizky et al. 2018. A comparisonof Various Forecasting Techniquesfor Coffee Price. IOP Publishing.Diakses dari:

https://www.researchgate.net/public ation/329490410_A_Comparison_o 
f_Various_Forecasting_Techniques _for_Coffee_Prices.

Putri, Rimadhita Tiara et al. 2019. Estimation of Indonesian Beef Price Forecasting Model. Jurnal AGRIYTOPICA.diakses dari : https://ejournal.unib.ac.id/index.php /jagritropica/index

Pardamean, M.,T,. 2010. Analisa Box Jenkins Pada Pembentukan Model Produksi Premi Asuransi Kendaraan Bermotor Roda Empat. Jakarta: Ejournal.Universitas Guna Dharma.

Sukiyono Ketut et al. 2018. Selecting anAccurate Cacao Price Forecasting
Model. IOP Publishing.Diakses dari:

ttps://www.researchgate.net/publicat ion/329490444_Selecting_an_Accur ate_Cacao_Price_Forecasting_Mod el/download.

Sukiyono Ketut., dan Rosdiana. 2018. Pendugaan Model Peramalan Harga Beras Pada Tingkat Grosir. Jurnal AGRISEP 17 (1). 23 - 30.

Yahmadi, M. 2005. Pemasaran Kopi Indonesia di Pasaran Global. Buletin No. 6. AEKI JawaTimur. 